\title{
The Temperature Dependant Efficiency of Photovoltaic Modules - a long term evaluation of experimental measurements
}

\author{
Jan Machacek, Zdenek Prochazka and Jiri Drapela \\ Brno University of Technology \\ Czech Republic
}

\section{Solar energy use, energetic potential of the Sun}

\subsection{The Sun as energy source}

All energy existing on the Earth comes from the Sun. This energy can be present in the chemical form in fossile fuels, as biomass energy in plants and animals, as luminous energy contained in the falling radiation or as thermal energy which affects processes in the atmosphere and the circulation of water in the environment. At the heart of the Sun, nuclear fusion takes place - the fusion of hydrogen nuclei during which helium and other heavier elements are formed. Every second, the Sun changes approximately 600 million tonnes of hydrogen into helium. According to the well-known Einstein's formula $E=m \cdot c^{2}$, the difference between masses can be converted to energy. That is, 4.26 million tonnes of mass is transformed on the Sun every second, which results in the production of about 3.8.1026 J of energy.

The Sun as a star is now in a stable phase of its development, which lasts some 4.6 billion years and is assumed to continue for about another 5 billion years. From the perspective of human life and human society it is therefore an inexhaustible source of energy.

It is assumed that at the end of this stable phase the Sun will approximately 1.4times enlarge its volume, exhaust the supply of hydrogen in its core, a thin layer of hydrogen enveloping its core ignites, the core shrinks as a result. The inner part of the Sun will expand and become a "red giant", who will engulf most of the planets in the solar system. The helium fusion will start in the helium envelope, with carbon and oxygen being formed. The thin envelope that will surround the burning core, will move out into space as a result of radiation effect. At the end of this process, only a carbon-oxygen core will remain of a $60 \%$ mass of the original Sun, wrapped in a thin hydrogen layer. This remainder will start cooling down and change into a "white dwarf", and after finally cooling down, the Sun will become a "black dwarf". The temperature on the Sun today is approx. $5900 \mathrm{~K}$ and its energy flows to as electromagnetic radiation. 


\subsection{Energy consumption of mankind}

The civilization of today needs ever more energy for its development and needs to find new and long-term sources of energy. At present, the greater amount of the electric power is produced in thermal and nuclear power stations. The consumption of the technosphere is stated to be approx. 10 TW (all the fossil fuels, biomass energy and energy present in foodstuffs). According to available sources, about $1.4 \mathrm{~kW} \cdot \mathrm{m}^{-2}$ energy (solar constant) falls onto the outer boundary of the Earth's atmosphere. The whole Earth's surface is exposed to a radiation power of $180.000 \mathrm{TW}$. Theoretically, the complete radiation power falling to the Earth's surface would amply cover the energy consumption of humankind.

\subsection{Use of solar radiation on earth}

If we want to start using solar energy on the earth surface, we first need to know its usable potential at the place of installation of equipment. There is a difference between the installation of photovoltaic panels outside the earth's atmosphere and right on the earth's surface. Beyond the outer boundary of the atmosphere the conditions of sunlight are fully predictable, the period, time and intensity of solar radiation can be accurately foreseen. Panels may only be screened by the Earth, or by another celestial body, which is predictable, and the screening does not last very long.

Also, it is no problem to provide a perpendicular position for panels in relation to the Sun. On the other hand, installation of panels on the Earth entails a number of other problems. Solar radiation which reaches the Earth through the atmosphere is affected by processes going on within it and by its pollution. Further it is necessary to consider the changing position of the Sun in the sky during the day and year (azimuth and altitude above the horizon). Also we have to consider the screening of objects around the place of the intended installation.

The radiation which falls on the Earth's surface, very much differs from the radiation coming from the Sun to the Earth atmospheric boundary. The atmosphere sends part of the radiation energy back into space, and absorbs or disperses part of it. Given these conditions, the amount of energy reaching the earth surface depends on the momentary state of the earth atmosphere. Part of the radiation is dispersed or absorbed by molecules of gases forming the atmosphere, or by solid or liquid substances present in atmosphere. All the radiation falling on the earth's surface is called global radiation. It consists of two components - direct and diffuse. The diffuse component is largely contained in the radiation under overcast skies. Under clear skies, slightly less than $1 \mathrm{~kW}$ of radiation power falls on a square meter, whereas under overcast skies the radiation power only amounts to tens of watts. 


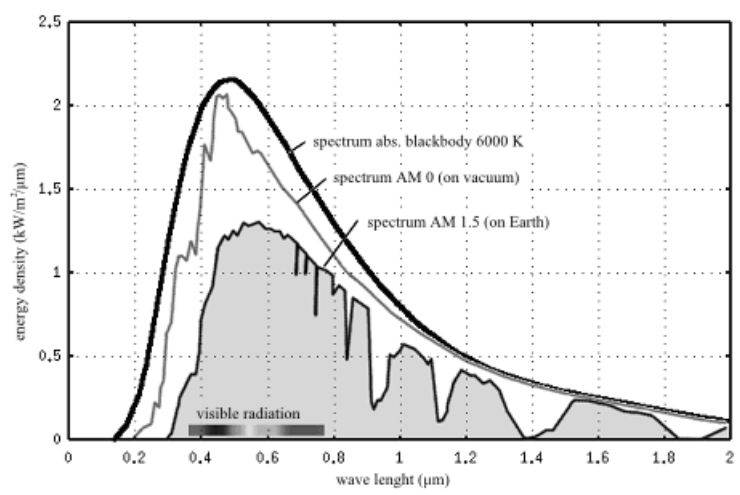

Fig. 1. Solar radiation spectrum after passage of earth atmosphere (Limbra M. and Poulek V. 2006).

Figure 1 shows the spectrum of solar radiation falling on the Earth, with wave length intervals marked that are absorbed by the atmosphere. The wave length representation is changed and the general radiation intensity decreases.

The altitude of the Sun above the horizon affects the radiation intensity. We can tell "the sunshine is stronger" at noon, when the sun reaches zenith, than towards the evening or in the morning, when it is just above horizon. Intensity of solar radiation throughout the day depends on its position in the sky, on the thickness of air layer which the radiation has to pass. A factor known as "Air Mass" is applied, which considers the effective quantity of air lying in the way of sun rays. When the sun reaches the highest point in the sky, an AM factor equals one. The amount of solar radiation hitting the ground also depends on altitude, i.e. this again relates to the amount of air sun rays have to pass through. When selecting a locality for photovoltaic panels installation, we have to consider the level of atmosphere pollution which is higher around conurbations than in the country, or the local climate of a relevant location and number of sunny and cloudy days in the year.

To identify the amount of solar radiation falling on the Earth, pyranometers are used, measuring both direct and diffuse radiation. They work on the principle of thermocouple and measure radiation of all wave lengths. If, however, we want to only measure direct radiation, we use a device called pyrheliometer, working on a principle similar to pyranometer. The latter is equipped with a tube which defines an angle under which radiation can enter the sensor. Further data needed to establish the amount of falling radiation can be obtained from meteorological measurements of long term climatic means for the locality in question (Murtinger K., Beranovský J. and Tomeš M., 2007).

\subsection{Physical nature of light}

Humans perceive light as the most natural of things, helping them recognize objects around them, distinguish between colours. Life without light is unimaginable to most of us. Light forms the visible element of electromagnetic radiation. Its physical nature was proved in the past and electromagnetic radiation has been used in many practical applications, first of all in information transfer. 
A time change in the electric field is accompanied by the magnetic field change and vice versa. The vectors of both the fields are perpendicular to each other and oscillation spreads perpendicularly to both vectors (direction of oscillation spreading is obtained through a vector product of the vectors of the electric field intensity and the magnetic field intensity). The wave length spectrum of electromagnetic oscillations is very broad, beginning approx. at $10^{-13} \mathrm{~m}$ and reaching across thousands of meters. Of course light (the visible spectrum of the electromagnetic radiation) only forms a narrow interval of the spectrum $\lambda=(380 ; 760)$ $\mathrm{nm}$, with each wave length within this interval corresponding with a specific colour of light. The shortest wave lengths correspond with violet, with wave length increasing the colour changes over blue, green, yellow and reaching far as red. We perceive sunlight as white, as it is composed of a continuous spectrum and contains all of its colours. Sunlight can be decomposed using a prism or diffraction grating, all colours of its spectrum being obtained (Limbra M. and Poulek V. 2006).

Overview of wave lengths and their technical specifications:

- Gamma radiation, wave lengths $\lambda<10^{-11} \mathrm{~m}$, use in nuclear physics, defectoscopy.

- $\mathrm{X}$ ray, wave lengths $\lambda=\left(10^{-11} ; 10^{-8}\right) \mathrm{m}$, medical diagnostics, defectoscopy, astronomy.

- Ultraviolet radiation, wave lengths $\lambda=\left(10^{-8} ; 10^{-7}\right) \mathrm{m}$, solarium, photochemistry, copying machines.

- Visible radiation spectrum, $\lambda=\left(3,8.10^{-7} ; 7,6 \cdot 10^{-7}\right) \mathrm{m}$, optics, photographic machines, light sources.

- Infrared radiation, $\lambda=\left(7,6 \cdot 10^{-7} ; 10^{-4}\right) \mathrm{m}$, thermal radiators, grills, remote controls, IR cameras.

- Microwave radiation, $\lambda=\left(10^{-4} ; 10^{-1}\right) \mathrm{m}$, microwave ovens, radar systems, mobile phones.

- $\quad$ Radio radiation, $\lambda>10^{-1} \mathrm{~m}$, radio, television, communication systems.

Electromagnetic waves have a dualistic character. They behave like waves and at the same time corpuscles. The wave character is more pronounced in greater length waves while the corpuscular character in shorter length waves. If a wave's character is corpuscular, energy within it instead of continuously spreads in quanta - parts that we see as 'quasi particles', i.e. particles/corpuscles with zero rest mass. Because of that, light has a corpuscular character, too, and therefore we can talk about a corpuscular-wave dualism.

Since light has a wave character, we can observe in it properties characteristic of general oscillation such as the laws of reflection and refraction at the boundary of two environments, interference phenomena, diffraction on the diffraction grating, and all the consequences of the Doppler effect such as e.g. a frequency shift toward the red edge of the spectrum known as the "redshift", or frequency changes caused by a star revolving around a centre of gravity alongside a big planet.

Manifestations of corpuscular nature of light belong to the field of quantum mechanics. Radiation is manifested as a flow of particles (quasi corpuscles) called photons. Their energy can be expressed by the relation $E=h \cdot f$, where $h$ is the Planck constant and $f$ is the radiation frequency. According to the relation $\lambda=c / f=c \cdot T$, the wave length is inversely proportional to the radiation frequency, i.e. we may state that photons with a shorter wave length (higher frequency) have more energy than photons with a longer wave length (lower frequency). It is thus possible to calculate that visible radiation photons have energy in $\mathrm{eV}$ 
order, gamma radiation photons dispose of energy in $\mathrm{MeV}$ orders and finally microwave radiation particles possess energies in $\mathrm{meV}$ order. An example of corpuscular character manifestation is just the photoelectric effect. At this point Albert Einstein must be remembered, who in 1921 won the Nobel Prize for clarifying this phenomenon (Limbra M. and Poulek V. 2006).

\section{Principle of photovoltaics and present-time technology}

\subsection{Physical nature of semiconductor function}

Electromagnetic radiation is converted to electric power in semiconductor photovoltaic cells on the basis of crystalline silicon. This kind of cell belongs to the most widespread. It will suffice for the purpose of explaining the principle of energy transformation. We can divide semiconductors into two groups, i.e. intrinsic and impure. Impure semiconductors may have $\mathrm{N}$ type conductivity - prevalence of negative charge carriers (free electrons), or $\mathrm{P}$ conductivity - prevalence of positive charge carriers (holes - a place of a missing electron). A silicon atom has a structure of diamond and contains 14 electrons, its last (valence) layer containing four electrons, forming covalent bonds with their neighbours. Under normal circumstances the energy of a free electron may acquire any random values. In a silicon crystal, however, an electron energy may only acquire specific values as a result of motion in a periodic potential. These energy levels are divided into "bands of permitted energies"i.e. energies an electron may acquire, and " bands of forbidden energies" - energies an electron may not acquire.

The following bands are relevant to the semiconductor function:

- Electron valence band (under very low temperatures it is the last to be occupied by electrons). It contains energy levels of valence electrons. The quantity of the levels is the same as that of valence electrons, they will be occupied under very low temperatures and will create covalent bonds with neighbouring atoms.

- Forbidden band of energies: an electron cannot acquire these energy levels.

- Conductivity band (under very low temperatures it is the first unoccupied). If an electron gets in this band, it may move freely through the crystal lattice space between atoms.

The energy level consistent with the last level of the valence band is marked $E_{V}$, the lowest level of conductivity band is marked $E_{C}$, the width of the forbidden band $\Delta E_{G}=E_{C}-E_{V}$. Another important energy level is the Fermi energy $E_{F}$. In an intrinsic semiconductor (e.g. pure silicon) the Fermi energy lies in the middle of the forbidden band.

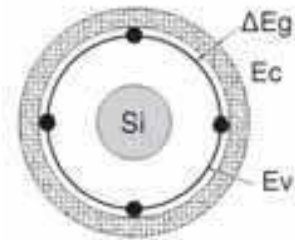

Fig. 2. Atom of silicon with represented energy levels. 
As a result of supplying energy, e.g. warming (by phonon), or lighting (by photon), an electron breaks the valence bond and moves to the conductivity bond. This is manifested in the energy diagram by electrons occupying higher energy levels. The valence and conductivity bonds thus become partially occupied. The electrons in the conductivity bond thus become electrons capable of carrying electric current. The free areas left by electrons in valence bands of some atoms, may be occupied by electrons jumping to them from other atoms. This is how the free areas move towards other atoms. In the electric field, free valence electrons move opposite the direction of electric field intensity, as they have negative charges. That is, free areas shift in the direction of field intensity. This place therefore behaves as a positive charge particle. The particle is called a "hole". In an intrinsic semiconductor the number of holes is equal to the number of free electrons. As a result, the crystal appears to be electrically neutral on the outside. If an electron - hole pair is generated as a result of a photon impact, the photon's energy must be greater than or equal to the forbidden band width. Photons with a smaller amount of energy will pass, while those with greater or equal energies are absorbed. the forbidden band width of silicon is approx. $1.1 \mathrm{eV}$. It is therefore transparent for photons with a wave length greater than $1100 \mathrm{~nm}$.

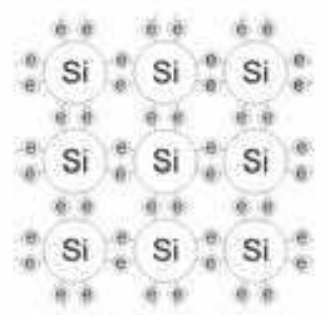

Fig. 3. Atoms of silicon inside intrinsic semiconductor.

Figure 4 shows a function which represents density of states - number of states per unit interval of energy for intrinsic semiconductor.

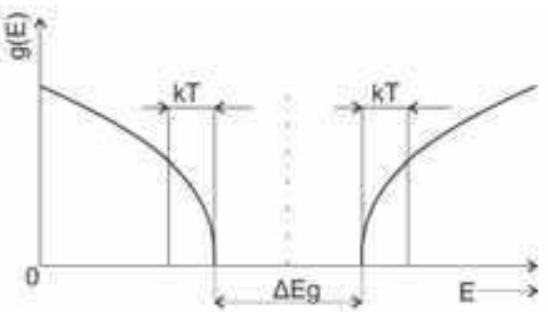

Fig. 4. Density of states for intrinsic semiconductor per unit interval of energy (Limbra M. and Poulek V. 2006).

Figure 5 represents a dividing function $\mathrm{f}(\mathrm{E})$ giving probability of energy level occupation by an electron. The probability that all the valence electrons will be occupied is high, as opposed to the probability that this will be in the conductivity band. This is consistent with the above mentioned theory saying that the valence band for the intrinsic one will under very low temperatures be the last occupied and the conductivity band the first to be not occupied. Dependence $1-f(E)$ represents the probability of an energy level not being occupied by an electron. Both curves cross at a value of 0.5 , which agrees with the value of 
the Fermi energy which for intrinsic semiconductor is in the middle of the forbidden band. Electrons pertain to the group of particles called fermions and behave in agreement with the Termu - Diracov statistics.

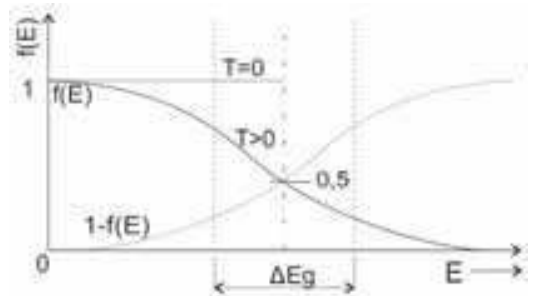

Fig. 5. Probability function $f(E)$ and $1-f(E)$ (Limbra M. and Poulek V. 2006).

The function $f(E) \cdot g(E)=n(E)$ in Figure 6 gives concentration of electrons in the conductivity band and the function $(1-f(E)) \cdot g(E)=p(E)$ concentration of holes in the valence band at a non-zero temperature. The areas below the curves are the same in intrinsic semiconductor. If we add a pentavalent element atom (a Group V element in the periodic table) to a pure silicon crystal, e.g. phosphorus, arsenic or antimony, a Type $\mathrm{N}$ semiconductor is produced. An element of admixture having an extra electron is called donor (i.e. donating one electron). Four valence electrons of arsenic create a covalent bond with the adjacent atoms of silicon, but one of them does not find a partner for bonding. That electron is only weakly attached to its atom and only a small amount of energy suffices to breaking it away. These free electrons effect electron conductivity (Type $\mathrm{N}$ non-intrinsic conductivity) through their motion. Presence of such admixture atoms is manifested in the energy diagram by local energy levels arising, lying in the forbidden band near the bottom limit of conductivity band $E_{C}$. There are a great many more donor electrons in the semiconductor than intrinsic electrons of silicon and therefore they are majority charge carriers. Semiconductors of Type $\mathrm{N}$ also include holes, though these arise as 'intrinsic charge carriers'. Their quantity heavily depends on temperatures. The holes are minority charge carriers in Type $\mathrm{N}$ semiconductors.

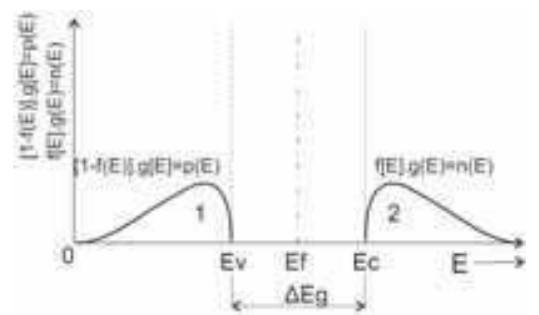

Fig. 6. Concentration of electrons and holes in intrinsic semiconductor (Limbra M. and Poulek V. 2006). 


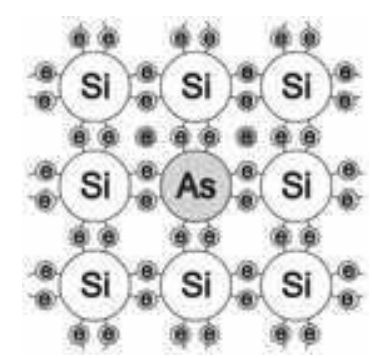

Fig. 7. Atoms of $\mathrm{N}$ type semiconductor with As donor atom (Dobiáš, 2008).

Figures 8, 9 and 10 present diagrams similar to those for intrinsic semiconductor, with the following difference for $\mathrm{N}$ type semiconductor: the Fermi energy level $\mathrm{E}_{\mathrm{F}}$ is shifted towards conductivity band, the donor energy level $\mathrm{E}_{\mathrm{D}}$ lies between $\mathrm{E}_{\mathrm{F}}$ and conductivity band. $\Delta \mathrm{E}_{\mathrm{D}}$ energy needed for transfer from this level to conductivity band is very small, of about $\Delta \mathrm{E}_{\mathrm{D}}=$ $0.01 \mathrm{eV}$.

For example, at room temperature an electron can easily go over to conductivity band. Given the small value of this energy, donor atoms are ionized at room temperature and create a positive space charge. The concentration of electrons in conductivity band is much higher than that of holes in the valence band. It can be seen in Figure 10 that area 2 delineating the electrons concentration, is higher than area 1, representing the concentration of holes.

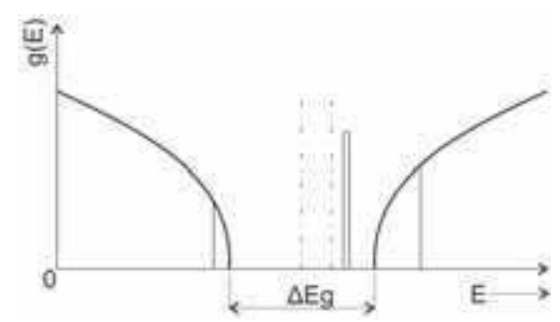

Fig. 8. Density of states in Type N semiconductor N (Dobiáš, 2008).

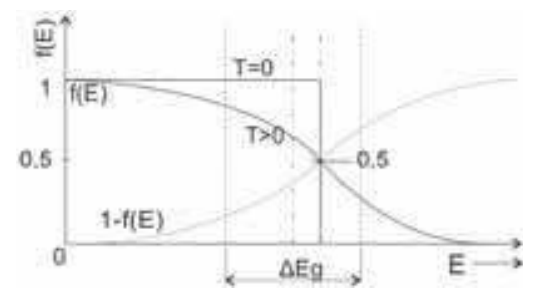

Fig. 9. Probability functions for Type N semiconductor (Dobiáš, 2008). 


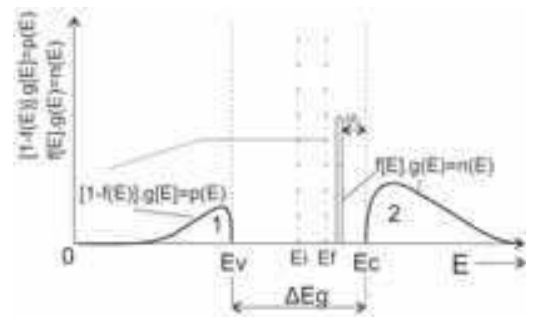

Fig. 10. Amounts of electrons and holes in Type N semiconductor (Dobiáš, 2008).

If in a tetravalent silicon crystal we replace some atoms by trivalent atoms of Group III elements in the periodic table (e.g. B, Al, Ga), Type $\mathrm{P}$ semiconductor is produced. Admixture atoms have one valence electron less than silicon, therefore it is called acceptor (it accepts one heat released electron in its valence layer). A trivalent element is not capable of creating a covalent bond of four pairs of electrons. The free place behaves like a hole (defective electron). Due to thermal energy effect a valence electron may jump over to the unfilled bond from the adjacent $\mathrm{Si}$ atom and the hole may move through the crystal. These holes of an alien atom create the hole conductivity in semiconductor (non-intrinsic conductivity of Type P).

Holes that are supplied to Type $\mathrm{P}$ semiconductor are many more than holes arising in intrinsic semiconductor. Therefore, in Type P semiconductor the hole is a majority charge carrier. There are also free electrons in P semiconductor, arising due to temperature effect, which are intrinsic charge carriers, while in Type P semiconductor they are minority charge carriers. Its amount depends on the semiconductor temperature.

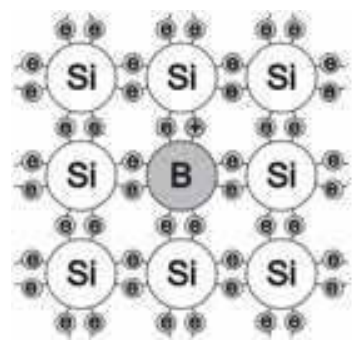

Fig. 11. Atoms in Type P semiconductor with acceptor atom B (Dobiáš, 2008).

Supply of trevalent element (Figure 11) is manifested in the energy diagram in a similar way as in Type $\mathrm{N}$ semiconductor. Acceptor level $\mathrm{E}_{\mathrm{A}}$ arises in the forbidden band, near the valence band. Only a small amount of energy $\Delta \mathrm{E}_{\mathrm{A}}$ is sufficient for electron jump-over from the valence band to this level. Such an acceptor atom appears outward as negatively charged. A solid negative space charge is produced. A hole thus generated in the valence band is free to move around. In Type P semiconductor, concentration of loose holes is much higher than concentration of free electrons, the Fermi energy $E_{F}$ level shifts towards the valence band. If one part of the crystal is doped by one type of admixture and the other one by an opposite type, the free charge carriers (electrons and holes) should based on the laws of diffusion escape from areas of higher concentration to areas of lower concentration. In this way an even spread is created. The escaping free charge carriers leave at the original 
sites firmly bonded charge carriers of opposite polarity, that will create a space charge. There are relatively strong local fields inside the crystal, which prevent further escape of admixture. The whole system will thus stabilize in a balanced state and appear as electrically neutral on the outside.

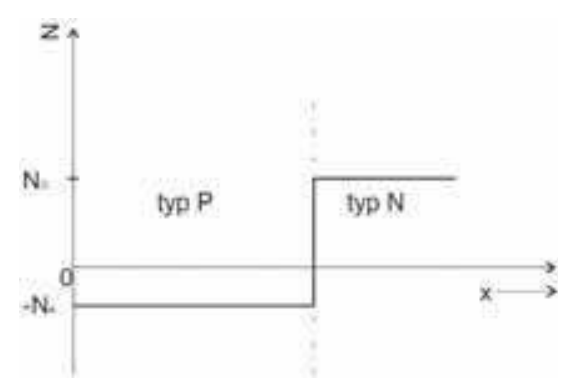

Fig. 12. Sharp division between the areas $N$ and $P$ (Dobiáš, 2008).

An example of such a differently doped crystal may be a semiconductor diode including a sharp divide between the areas $\mathrm{P}$ and $\mathrm{N}$. Streams of free charge carriers flow over the PN junction in both directions, Figure 13 shows a situation for free electrons. As for holes, it will be similar. Some free electrons from area $\mathrm{N}$ pass to area $\mathrm{P}$ where they recombine with free holes (recombination flow of electrons). But then, as mentioned before, electron in area $\mathrm{P}$ is the minority charge carrier which is attracted to area $\mathrm{N}$, where is the firmly bound positive charge. This electron flow is called thermal. Without an added external voltage the two currents are balanced and not shown on the outside.

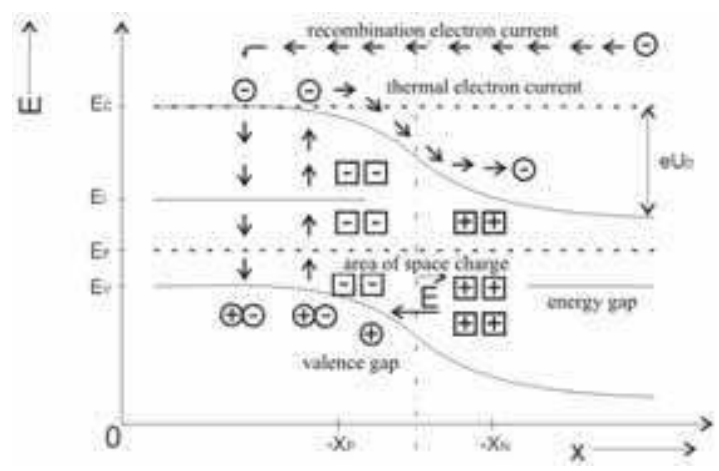

Fig. 13. Unpolarized PN junction (Dobiáš, 2008).

If we apply the external voltage on part $\mathrm{P}$ with the positive pole and on part $\mathrm{N}$ with the negative pole, the band will curve as a result and the internal diffusion voltage $U_{D}$, will be reduced, whereby the recombination electron flow from Type $\mathrm{N}$ semiconductor to Type $\mathrm{P}$ while the flow of holes from $\mathrm{P}$ to $\mathrm{N}$ prevail. PN junction has thus been polarized in the transparent direction. When applying external voltage of opposite polarity, potential barrier $\mathrm{U}_{\mathrm{D}}$ increases, recombination flow drops and thermal flow of free charge carriers prevails. 


\subsection{Principle of the photovoltaic cell function}

The photovoltaic cell can be imaged as a large-area PN junction positioned perpendicularly to the face of the cell between the front and back walls, while Type $\mathrm{N}$ semiconductor faces the front wall and Type P semiconductor the back wall of the cell. The falling photons with an energy greater than corresponding to the forbidden band width $\Delta E_{G}$, generate an electron-hole pair. This is how photons deliver their energy and are absorbed in PN junction. They give the remainder of their energy if any to the crystalline grating, where it is transformed to heat. Electron-hole pairs are separated from each other by an internal electric field at PN junction. Holes are accelerated in the direction of while electrons in the opposite direction to the internal field $\vec{E}$. Electric voltage appears between the cell poles and after connecting the cell to circuit, electric current starts passing through it.

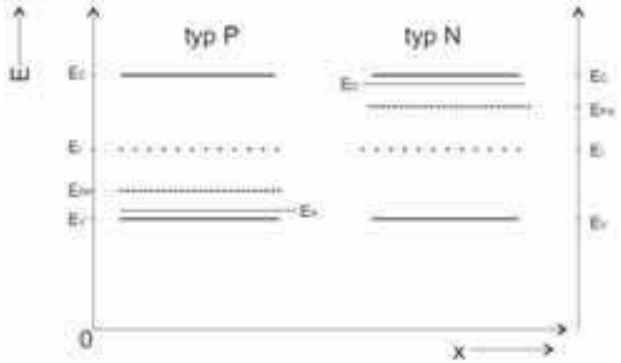

Fig. 14. Diagram of semiconductor cell energy levels (Limbra M. and Poulek V. 2006).

Figure 14 represents a diagram of energy levels in types $\mathrm{P}$ and $\mathrm{N}$ semiconductors. Figure 15 shows equalization of the Fermi energy and the band curve in an unlit photovoltaic cell. Also the recombination and thermal flows in a balanced state are represented. I.e. semiconductor cell behaves in the dark like a semiconductor diode.

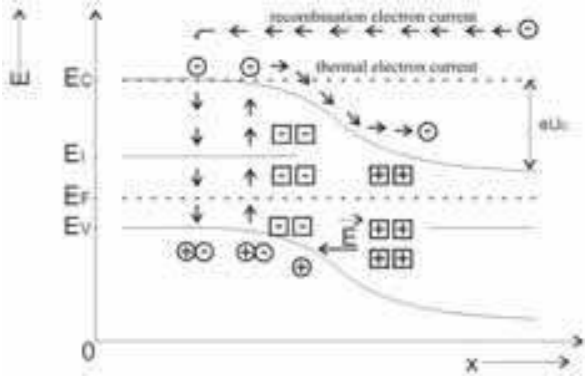

Fig. 15. Unlit photovoltaic cell (Limbra M. and Poulek V. 2006).

Figure 16 presents a diagram of energy levels of the lighted semiconductor cell, not connected to circuit. The falling electrons break the internal balance of charges, or exactly create a different one. The generated holes are accelerated in the direction of the internal field $\vec{E}$ (which corresponds to thermal flows in the reverse direction). Type $\mathrm{P}$ semiconductor is charged positively and Type $\mathrm{N}$ semiconductor negatively. Potential barrier $U_{D}$ decreases, the Fermi levels in areas $\mathrm{P}$ and $\mathrm{N}$ are divided and their difference equals 
photovoltaic voltage $U_{P}$. The voltage can reach a maximum of $U_{P} \approx 0,6 \mathrm{~V}$, which equals the original bands equalization. By further increasing intensity of the cell lighting the voltage does not increase. This is because reducing the potential barrier by voltage $U_{P}$ the recombination current and the system enters the new stable condition.

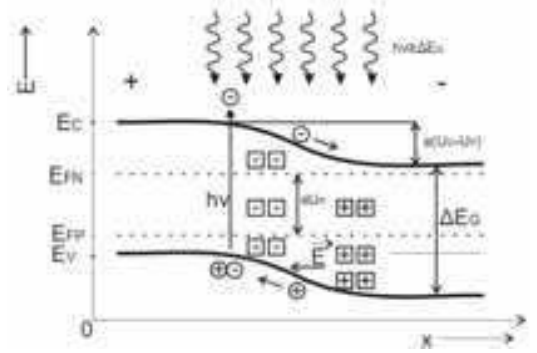

Fig. 16. Lighted photovoltaic cell (Limbra M. and Poulek V. 2006).

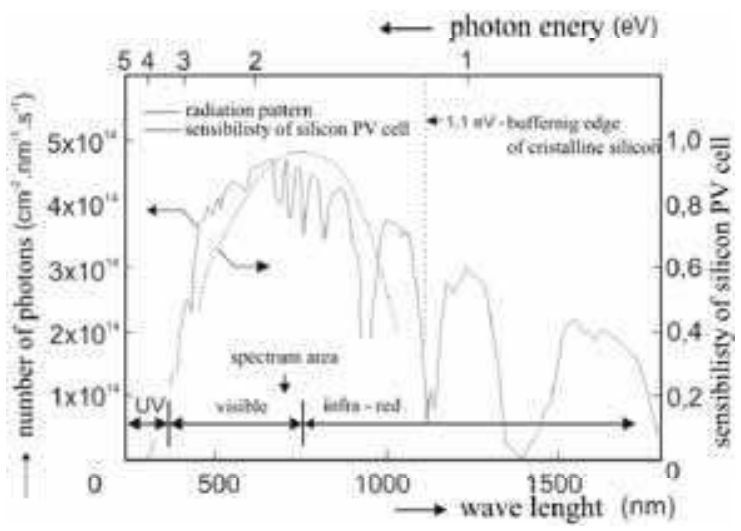

Fig. 17. A solar radiation spectrum after passing through atmosphere, which the photovoltaic cell is able to absorb (Limbra M. a Poulek V. 2006).

After connecting the lit semiconductor cell to the electric circuit the photovoltaic voltage (electromotoric voltage of the source) decreases, the band curve changes and the potential barrier increases again. This effects decrease in recombination flows and thermal flows predominate as a result of separation of the generated free charge carriers by the internal firmly bonded space carrier. The sum of recombination and thermal flows will no longer be zero and the resulting flow will run through the connected electric circuit. As mentioned above, the forbidden band width equals $\Delta E_{G}=1,1 \mathrm{eV}$, photovoltaic panels are therefore sensitive to radiation of wave lengths shorter than $\lambda=1100 \mathrm{~nm}$. Figure 17 presents a solar radiation spectrum after passing through atmosphere with a marked area which the silicon photovoltaic cell is able to absorb. 


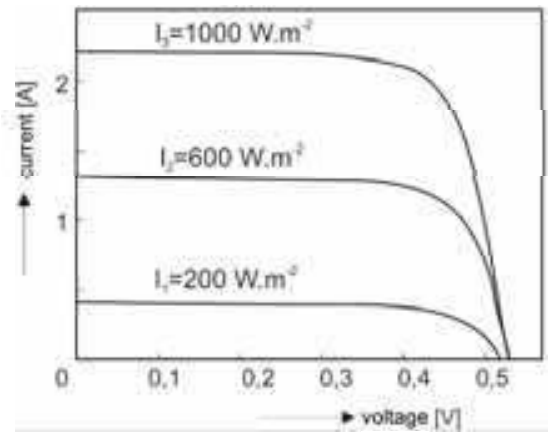

Fig. 18. Loading characteristics of photovoltaic cell for different lighting intensities (Dobiáš, 2008).

Figure 18 represents the loading characteristics of a lit cell at different lighting intensities. Points of intersection of curves and the vertical axis specify swift currents while off-load voltage is specified by horizontal axis points of intersections. An optimum load for semiconductor cell has a value at which the working point lies in such an area of the loading characteristics, where the product of voltage and current reaches the highest value. This being reached, the cell delivers a maximum power to the circuit.

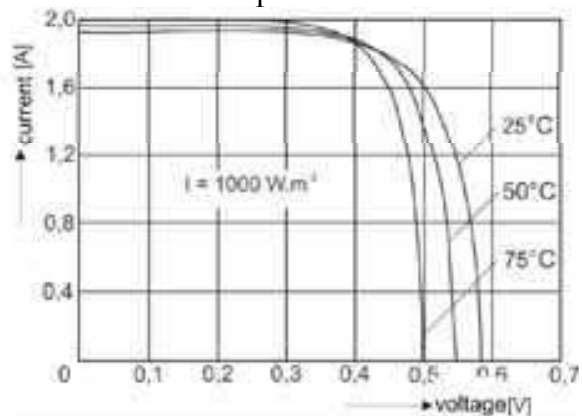

Fig. 19. Change in load curve in relation to temperature (Dobiáš, 2008).

Figure 19 shows how load curves change in relation to heat. At higher temperatures the semiconductor cell is able to deliver higher swift current, however, its off-load voltage will drop. With temperatures rising and constant intensity of solar radiation the maximum power the cell is able to supply to the circuit is falling. I.e. the efficiency of photovoltaic energy transformation decreases.

\subsection{Production of photovoltaic cells}

The silicon panels are among the most widespread types and can be divided into 3 basic groups: monocrystalline, polycrystalline panels and panels on the basis of amorphous silicon. Silicon is found most abundantly on the Earth, that is why it is inexpensive, it is not toxic and up to now has been the most widely used and explored semiconductor. Silicon is also suitable due to its forbidden band width of $\Delta E_{G}=1,1 \mathrm{eV}$. In the natural environment, silicon most frequently occurs in the form of silica or silica sand (SiO2). The raw silicon, 
suitable for technological purposes, is produced in an arc furnace through reduction with carbon $\mathrm{SiO} 2+\mathrm{C} \rightarrow \mathrm{Si}+\mathrm{CO} 2$. Silicon gained in this way is $99 \%$ pure, amount of impurities is $1 \%$. Purity needed for use in semiconductor technology is much higher. Today one of the most widely used technologies to increase silicon purity is Siemens with chlorine cycle (Figure 20). The chlorine process, though the most commonly used at present, is technologically extremely demanding and dangerous for operator staff as well as the environment. New technologies of pure silicon production are in development, now in the phase of testing and trial production. If proved effective, they may bring cuts in energy demand and price of pure silicon. The production process typically yields lumps of pure silicon, further processed in creation of monocrystalline or polycrystalline ingots.

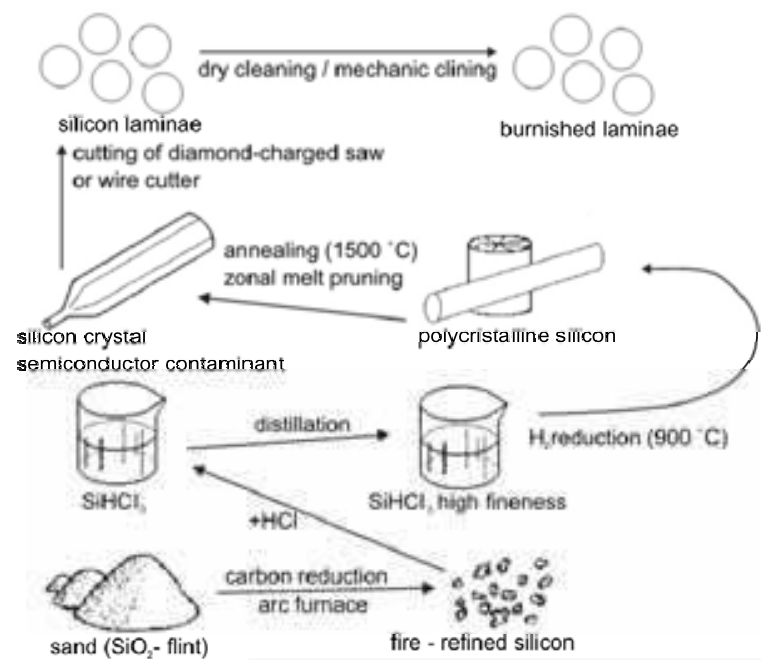

Fig. 20. Silicon production cycle (Limbra M. and Poulek V. 2006).

The production of polycrystalline ingots is substantially simpler than that of monocrystalline. The molten material is simply poured in a mould and left to cool down at a defined rate. Cooling must be as slow as possible, in order for the largest possible monocrystalline grains to be created and a minimum dislocations reached in the material. Monocrystalline ingots are produced with the Czochralski method. A small monocrystal nucleus is dipped in a melting of an approximate temperature of $1415{ }^{\circ} \mathrm{C}$. The nucleus is turned around very slowly and drawn out of the melting. The whole process of drawing takes place in an inert atmosphere, in order to ensure silicon purity.

\subsection{Construction of photovoltaic panels}

The produced monocrystalline or polycrystalline ingots are cut into wafers that create the basis for semiconductor cells. Wafers are usually cut $100 \mathrm{~m}$ thick. Semi-finished products for semiconductor production from different materials are made using technologies similar to those for silicon. As mentioned before, the semiconductor cell is a large-area diode with PN junction in a perpendicular position toward the facing. The admixture elements are added to semiconductor in diffusion furnaces. On the cell's face is applied antireflex coating in order 
to minimize reflection, i.e. make use of a maximum amount of the falling radiation. Cells of greatest efficiency therefore appear to be black. Sometimes a thin transparent coating is applied on the face for decoration purposes, to enhance the reflected radiation of a specific wave length as a result of wave interference on this coating. Such cells then produce a sort of colour shade in the reflected light. The contact on the front side is usually shaped as a lattice or comb in order to cover the smallest possible surface of the cell face. The back contact on standard panels typically covers the whole surface. Contacts are applied by serigraph onto cells. Only for more demanding applications vacuum technologies are used such as vacuum fomentation. For special cells with high radiation concentrations contacts embedded in semiconductor material are made. This enlarges the contact surface between contact and semiconductor because of great densities of current flowing through such cells (Bařinka R. and Klimek P., 2007).

\section{a) simple model}

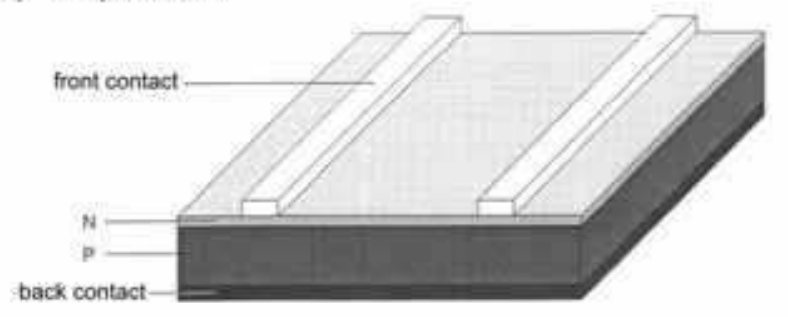

b) cell with high efficiency

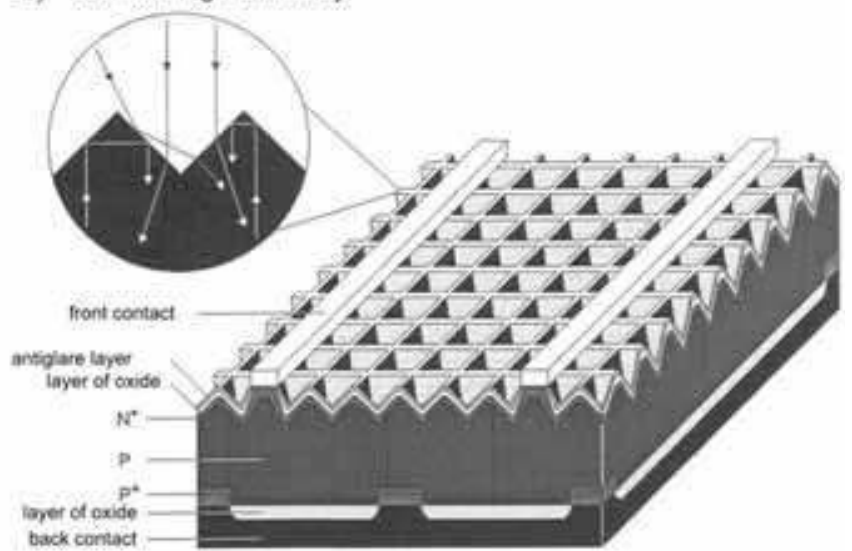

Fig. 21. Simple cell and high efficiency cell (Limbra M. a Poulek V. 2006).

The conventional semiconductor cell is shown in the upper part of Figure 21. This simple cell works based on the above described principle, but its efficiency of photovoltaic transformation is lower mainly because of recombination losses. In order to increase the efficiency, in higher quality cells (Figure 21b) constructional improvements are used to minimize reflection caused losses. The antireflex coating on their surface reduces reflection so as to allow the largest possible amount of photons to penetrate into the area of PN 
junction. The layers of nonconductible $\mathrm{SiO} 2$ chemically deactivate the cell surface while the layers are only etched at some points and it is just through them the electric charge is conducted away. The structure of small pyramids etched in the cell face causes photons easily entering the cell, however if they have passed through PN junction and have not been transformed, they are reflected from the back electrode, but do not pass back out through the cell face because of the total reflexion. Photons are reflected back to PN junction and probability of photovoltaic transformation thus increases. In double-sided panels, the structure of pyramids is etched on both sides, i.e. photons can fall from both sides, e.g. on the back side by reflection from the ground. Thus the amount of energy produced is higher, although photovoltaic efficiency of transformation on the back side is lower, as photons of shorter wave lengths are absorbed in the thicker layer of the semiconductor substrate and will not reach PN junction.

In polycrystals, boundaries of grains weaken the transport qualities of semiconductor, in amorphous semiconductors the conditions are even worse. The efficiency of present-time quality monocrystalline cells is around $20 \%$. In laboratory conditions, efficiency of up to 30 $\%$ can be reached. Cell efficiency on the basis of other semiconductors $(\mathrm{GaAs}, \mathrm{InP})$ is even higher. It reaches values around $25 \%$ as for cells series production, though their price is several times higher. That is why these cells are mainly used in cosmic applications where the price is not a limiting factor. They are also used in "tandem alignment", where cells on various bases are aligned one after another, each of them using a different part of the spectrum. Besides silicon, CuInSe or CdTe cells or cells with heterojunctions between different kinds of semiconductors are used in thin-layer applications. The cells are relatively cheap, however, they reach smaller efficiency of around $10 \%$, and have very unstable parameters. A cell with about $15 \%$ efficiency can be produced, but its efficiency will drop below $10 \%$ in a short time.

Photovoltaic panels are produced by placing individual cells inside them in a series-parallel combination, so that they deliver the required uniflow voltage and current at defined lighting. The most common photovoltaic panel is made of a front tempered glass which withstands great impacts and is resistant to hail. Onto the glass is applied an EVA (ethyl vinyl acetate) foil onto which individual interconnected cells are laid next to each other. The cells are covered by another EVA foil and the back wall of the cell is usually made of PVFPET-PVF laminate composition. Next, air is exhausted between the two layers and the panel is warmed up to the temperature of EVA foil melting. EVA foil will melt away as sealing compound and fill the space between the front and back panel sides. Finally, panels are framed and sealed with a silicon sealant in aluminium sections and have a box with outlet contacts fitted. In this way panels are sealed tight to prevent penetration of water and dirt. Panels on the crystalline silicon basis have a service life of 20 to 30 years.

Double-sided panels consist of double-sided semiconductor cells and taking into account efficiency of photovoltaic transformation, they are more advantageous than the one-sided panels now in use. Curiously, their difference in price is not so great. The production technology of double-sided panels only differs in transparent laminate used in its back wall, and the lattice-shaped back contacts not covering the whole surface, as mentioned before. The panel is optimized to take radiation from the front side, still the efficiency of photovoltaic transformation with radiation reaching the back side is not much smaller. Double-sided c-Si based panels are within the infrared area of the spectrum for radiation of a wave length higher than $\lambda=1100 \mathrm{~nm}$, i.e. with energy smaller than that of the forbidden 
band width. This radiation amounts to over $20 \%$ of solar radiation energy and proportionally to that, less energy transformed to heat is absorbed in double-sided panels as compared with single-sided panels. Double-sided panels therefore have a lower temperature and the relating higher efficiency of photovoltaic energy transformation.

Innovative is the connection of monocrystalline balls with spherical PN junction. The balls can be rigid with a glass front wall, or flexible, enclosed in plastic with a teflon face. The balls of silicon have an approx. $0.6 \mathrm{~mm}$ diameter, with Type P semiconductor inside and Type $\mathrm{N}$ semiconductor on the surface. That is, they have spherical PN junction under the surface. Balls are produced by dropping a doped admixture from the capillary tube, which stiffens during fall. After that diffusion takes place and the ball surface is redoped to Type $\mathrm{N}$ semiconductor. Balls are then placed onto an aluminium foil with holes smaller than the ball diameter. The foil creates negative electrode, as it touches Type $\mathrm{N}$ semiconductor. On the other side of the ball part $\mathrm{N}$ is etched away and a contact installed in Type P semiconductor, which creates positive electrode. The whole cell is then enclosed; there are rigid or flexible panels of different sizes made of these cells. The efficiency of such panels has reached around 14 \% so far (U.S. Department of Energy, 2006).

\subsection{Basic types of photovoltaic cells}

The photovoltaic cell has a development history of 50 years during which a large number of construction types using different materials have been developed. The earliest type is photovoltaic cells on the basis of monocrystalline silicon, with a large-area PN junction created inside. The cells are characterized by good efficiency and long-term performance stability. They are still used in large-area installations. Their disadvantage is great consumption of very pure silicon and relatively demanding production.

The great consumption of silicon and high demands on its production stimulated the use of thin-layer cells. Cells of monocrystalline, polycrystalline or amorphous silicon are among the most commonly used. Their main disadvantage consists in their significantly smaller efficiency and smaller stability of parameters (efficiency continues to decrease over time). These cells are beginning to be used in applications where flexibility is required. Owing first of all to the interest of the army there are cells in development that are part of clothes or backpack and enable supply for pack sets.

There are systems that use methods other than PN junction for charge separation, and frequently they are not even semiconductors. These include e.g. photoelectric (photogalvanic) cells or polymer cells. Nanostructures begin to be used, in the form of carbon nanotubes or nanosticks, or application of quantum dots on a suitable pad. These structures are liable to easy influencing their electrical and optical properties. Still, their practical use has been barely noticeable so far, the problem again being their low efficiency and small stability of properties and life. Possibly the closest to commercial use are now the flexible photovoltaic modules based on organic polymers.

The greatest potential for future use is seen in the composite photovoltaic cells which are able to effectively use a broad range of the solar spectrum. Each layer can only use light in a specific wave length range. The radiation that a layer is not able to use will pass to the next layers where it is utilized. 


\section{Dependence of PC output current and efficiency on its temperature}

\subsection{Substitute circuit of photovoltaic cell}

The output power of a photovoltaic cell and / or a cells module primarily depends on two factors, i.e. the cell heat and the intensity of solar radiation falling onto its surface.

The relation between the cell temperature and the output current and consequently the power has been described in literature using a substitute circuit, see Figure 22. Figure 22 represents a photovoltaic cell substitute circuit consisting of a current generator in parallel connection with a resistor and diode (Luque A, Hegedus S., 2002).

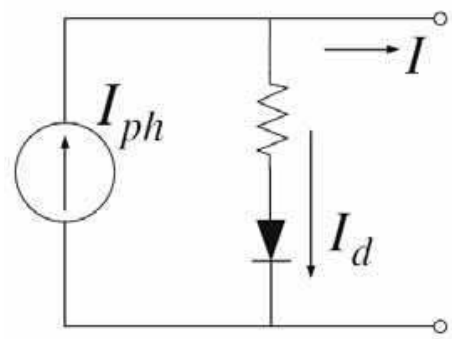

Fig. 22. Substitute circuit of photovoltaic cell.

Photovoltaic current $I_{p h}$ is directly proportional to the intensity of solar radiation $\mathrm{S}\left(\mathrm{kW} / \mathrm{m}^{2}\right)$ and can be expressed as (Markvart T. Solar electricity., 2000):

$$
I_{p h}=\left[I_{s c r}+C_{i} \cdot \frac{T-T_{r}}{1000}\right] \cdot S
$$

where $T$ is a cell temperature, $T_{r}$ is reference temperature, $I_{s c r}$ is swift current under reference operation conditions $\left(1 \mathrm{~kW} / \mathrm{m}^{2}, \mathrm{AM} 1.5,298 \mathrm{~K}\right) . C_{i}$ is a temperature coefficient of swift current. The following relation applies to estimation of a cell temperature from the ambient temperature $T_{a}$ :

$$
T=T_{a}+\frac{N O C T-20}{0.8} \cdot S
$$

where NOCT is nominal operating temperature. Let us assume a parallel shunt resistance is interminable, therefore the current through this resistance can be omitted, and the current through diode $I_{d}$ and the reverse saturation current $I_{s a t}$ can be expressed as follows:

$$
\begin{gathered}
I_{d}=I_{\text {sat }} \cdot\left[\exp \left(\frac{q \cdot V}{K A T}\right)-1\right] \\
I_{\text {sat }}=I_{r r} \cdot\left(\frac{T}{T_{r}}\right)^{3} \cdot \exp \left[\frac{q \cdot E_{g}}{K A} \cdot\left(\frac{1}{T_{r}}-\frac{1}{T}\right)\right]
\end{gathered}
$$

where $q$ is an electron charge value, $V$ is output voltage, $K$ is the Boltzmann constant, $A$ is ideality factor, $I_{r r}$ is reverse saturation current at reference temperature, $E_{g}$ is size of gap between the conductivity and the valence bands. The following relation applies to output current: 


$$
I=I_{p h}-I_{d}
$$

As follows from the above derivation of output current dependence on temperature, if the temperature of photovoltaic cell increases, swift current will decrease, which results in the decrease of maximum cell output power and efficiency of energy transformation. By contrast, with the growing intensity of falling radiation, swift current as well as maximum output power increase and conversion efficiency rises.

The above conditions, unfortunately, act against each other, and moreover at the least favourable point in time. It is at the point of the greatest sunshine and falling of the greatest intensity of solar radiation on photovoltaic panel surface, i.e. the time of the expected maximum power gain, when due to sunrays effect the warming culminates and the panel electrical specifications change, which results in the above mentioned decrease in conversion efficiency and consequently decrease in the supplied power. The resulting power under these operating conditions is then smaller by percent units than possible maximum power which the panel might provide at the current intensity of falling radiation. The following figures and characteristics represent the described problems graphically. Figure 23 shows VoltAmper and power characteristics of a monocrystalline solar cell under reference operating conditions (Chan DSH, Phillips JR, Phang JC., 1986).

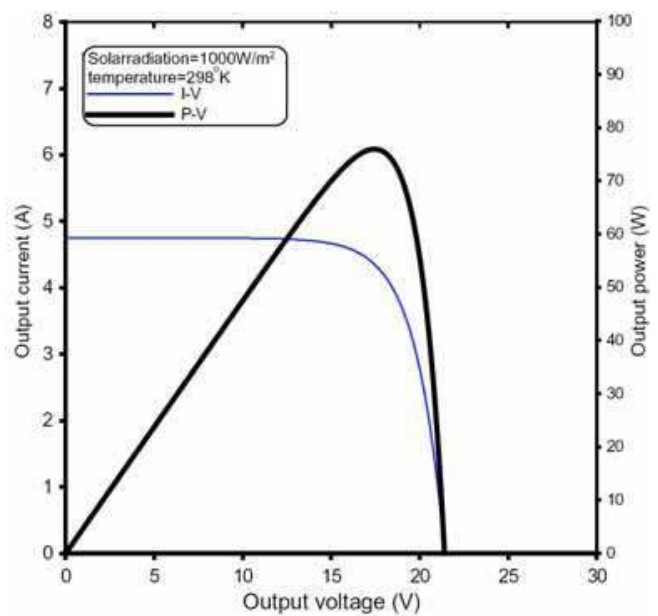

Fig. 23. Specific VoltAmper and power characteristics of photovoltaic cell (Chen YM, Lee $\mathrm{CH}, \mathrm{Wu} \mathrm{HC} ., 2005)$.

The level of efficiency change in relation to temperature depends on several factors. It depends e.g. on material composition and cell structure of crystalline silicon of photovoltaic cell. Typical decrease of efficiency in standard cell types ranges between 0.4 to $0.6 \%$ of power per degree Celsius of the growing cell temperature. As to new types of cell that are very thin and have a lower temperature coefficient, the power drops by only approx. $0.2 \%$ per degree Celsius. 


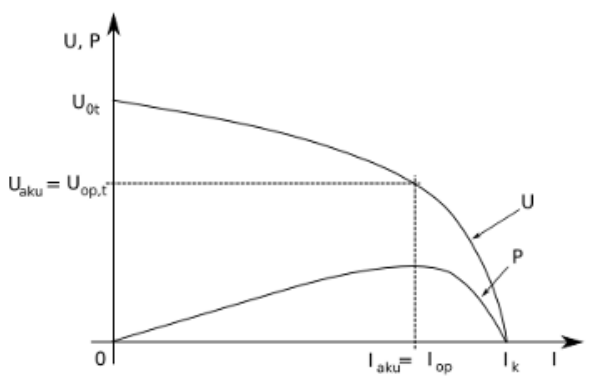

Fig. 24. Load and power characteristics of a typical photovoltaic cell.

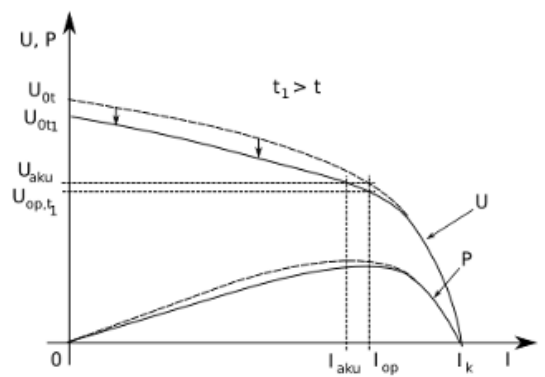

Fig. 25. Effect of temperature change on VoltAmper characteristics of a typical photovoltaic cell.

Figures 24 and 25 demonstrate the impact of drop of falling solar radiation intensity, where alongside the decreasing intensity the potential maximum power which a photovoltaic cell is able to produce decreases too, and the impact of the mentioned temperature on the working point shift on the power curve and the drop of an output voltage optimum value. The level of operating temperature of a photovoltaic cell or cell array depends on the climatic conditions of a relevant locality, the degree of intensity of falling solar radiation on the one hand, and on the design, construction and assembly of the panel on the other. These factors actually have a substantial impact on the module's ability to cool and transmit heat to the ambient environment, in most cases air, and on determining the definitive panel operating temperature under specific climatic conditions. The measure of efficiency of the construction for panel cooling is known as Nominal Operating Cell Temperature - NOCT, which is determined for the defined intensity of falling solar radiation, temperature, weather and atmospheric conditions (Tian Pau Chang, 2008).

\subsection{Possibilities of energy use optimization}

An optimization device can be used to compensate for this effect, working on the principle of an increasing $D C / D C$ of the converter. The solution is based on the electronic power regulation of photovoltaic generator loads with regard to their current operating conditions. The function of an optimization circuit is shown in Figure 26.

Connection (see Figure 26) is the basic form of a non-insulated increasing converter. It can be classed as indirect converter of input-to-output energy transfer, as the energy is accumulated in the coil's magnetic field. During the transistor closing the current I_zap is 
increasing. Energy is thus gradually accumulated in the coil's magnetic field, the coil therefore behaving like an appliance. Now current is only supplied to the load from Condenser $\mathrm{C} 1$. Condenser $\mathrm{C} 1$ is thus being discharged and its current drops in the same way as the voltage on it.

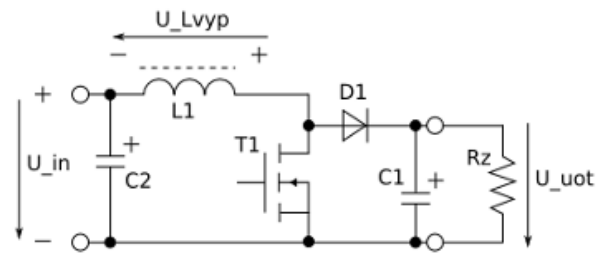

Fig. 26. Increasing converter diagram.

When opening the transistor current flows from the source of input voltage U_in and coil L1 to the load. Coil L1 keeps the flow direction of its current, but it reverses its polarity of voltage (passes from the appliance mode to the source mode), its induced voltage U_Lvyp adds up to voltage of the supply unit U_in and diode D1 passes to conducting state. The coil now behaves like a source series-connected to the source of supply voltage U_in. In this activity phase, current flows to the load and output condenser from these series-connected voltage sources. That is, Condenser C1 is recharged by current I_vyp and voltage increases on it as well as Load Rz. Diode D1 prevents discharging of Condenser C1 through the transistor in the case of the transistor being closed. If the output voltage is determined by the level of accumulator charging, input voltage on Condenser C2 can be reduced through the pulse control of Transistor T1, so that it meets just the optimum operating voltage of the photovoltaic generator. The benefits of this increasing connection are as follows: simplicity, low price, ability to reach voltage increase on the output as against the input voltage without the necessity to use the transformer.

In order to verify the function of optimization, the increasing converter connection has been carried out, whose functional diagram is shown in Figure 26. The complete optimization connection consists of the power and control parts (see Figure 27). The power part is made up of an increasing converter which is connected between the photovoltaic cell and a pair of $12 \mathrm{~V}$ series-connected accumulators. The control part is supplied directly from PV cell and comprises a processor and two magnifiers. The processor used (PIC16F877) is an 8-bit RISC microcontroller, time controlled from a $20 \mathrm{MHz}$ crystal. The processor contains many modules, of which only A/D converter and the module for pulse-width modulation (PWM) are used, the latter being set for $78 \mathrm{KHz}$ frequency at 8bits differentiation (also $39 \mathrm{kHz}$ setting is being tested at 9 bits differentiation). A/D converter has a supply of external reference voltage added. The value of charging current supplied to A/D converter, goes over the magnifier and the filter. The process has an array of 8 diodes connected, telling us which pulse-ratio PWM is just using. PWM signal controlling the increasing converters goes over the digital magnifier. 


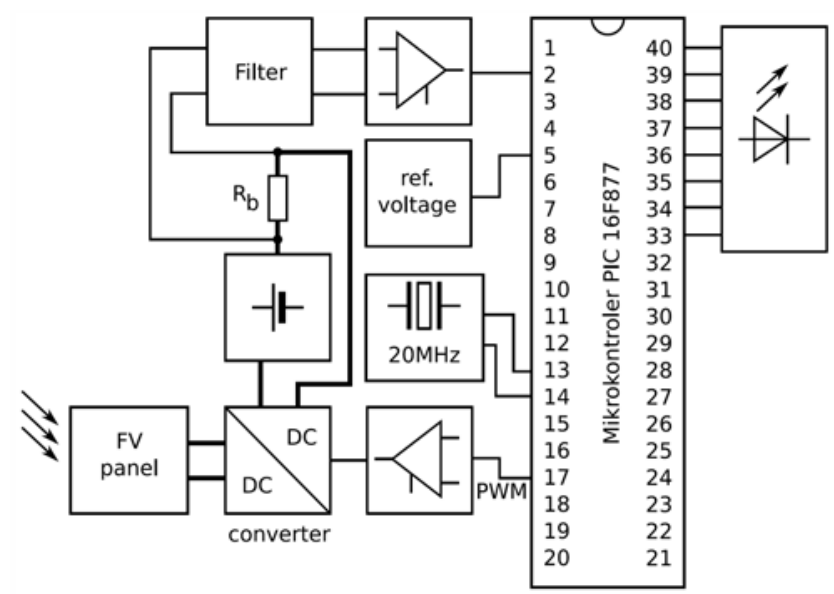

Fig. 27. Optimization circuit.

\section{Measurement system for long-term measurement, archiving, processing and visualization of data}

In order to verify the above described conditions and for other experimental purposes, a "measurement" system has been set up at the Department of electrical power engineering of BUT, Brno, which records, further processes and displays the measured data. Viewing of data and a great amount of other relevant information is effected through the Internet interface on the Department's site at http://www.ueen.feec.vutbr.cz/laboratory-ofunconventional-energy-conversion.

Unfortunately, the system is currently out of operation because of its planned relocation and mainly its upgrading to a more advanced version; that is why online display of values is not available at present, still viewing of values measured in the past is functional.

Online measurement alone is taken on a PV panel by Solartec $\left(\mathrm{SP} 17-100, \mathrm{P}_{\mathrm{mpp}}=100 \mathrm{~W}_{\mathrm{p}}, \mathrm{U}_{\mathrm{nom}}=\right.$ $24 / 12 \mathrm{~V}$, Max.sys.vol $=750 \mathrm{~W}, \mathrm{~S}=0.845 \mathrm{~m}^{2}$ ), installed on a roof terrace of Building $\mathrm{U} 2$ within the Dean's office precincts of Brno University of Technology, No. 53 Údolní Street, Brno. The measurement programme reads values from several sensors (see diagrams). In the first place intensity of solar radiation and immediate panel power output are read, the measured data of primary relevance to us, and air temperature and panel temperature are supplementary measured quantities. A temperature-sensitive element for measuring air temperature is installed in a protective "house", in order to eliminate the influence of airflow, rain and direct sunshine. PV panel temperature is another measured value. A temperature-sensitive element is actually placed in the middle of PV panel, on its upper (lighted) side.

For interest's sake we measure the temperature of the lower (unlit) side of the panel too, though these values are not included in the diagrams. Immediate power output of the panel is measured both as actual and optimized values. The actual power is measured in the standard PV panel - accumulator connection. All values are saved in the database and immediately displayed on the Internet.

Data flow through the system is approx. the following: measured quantities are transferred using a separator multiplexer to the measurement system formed by NI-6023E plug-in 
board. Signals from all the measurement sensors are brought to analogue inputs of the measurement board within a 180-second time loop. The board digitalizes the signals and transmits the raw data to the control programme (script in the Matlab). The script not only communicates with the measurement board thus controlling the whole measurement, furthermore it controls the operation of the optimizing circuit through the card's digital outputs. In order to archive the data in an organized way and further process it, the script sends it to MySQL database on the server and the whole loop is repeated. The data saved in the database can be further processed independently of the ongoing measurements, i.e. carry out all kinds of sorting and additional computations etc. The data arranged and prepared in this way can be presented on-line in practically real time.

In our case, we make several supplementary calculations. In relation to the measured powers, intensity of falling solar radiation and temperatures we further calculate the following:

- panel produced daily energy,

- energy gain from equipment optimization,

- cumulative and immediate efficiency of energy transformation,

- monthly sum of panel produced energy,

- monthly sum of energy gain from equipment optimization,

- monthly sum of cumulative and immediate efficiency of PV panel energy transformation,

- yearly sum of panel produced energy,

- total of panel produced energy.

\subsection{Results of long-term measurements}

This chapter presents several sample diagrams with measured or calculated values of daily characteristics and further diagrams representing already long-term results within timeperiods of up to one year.

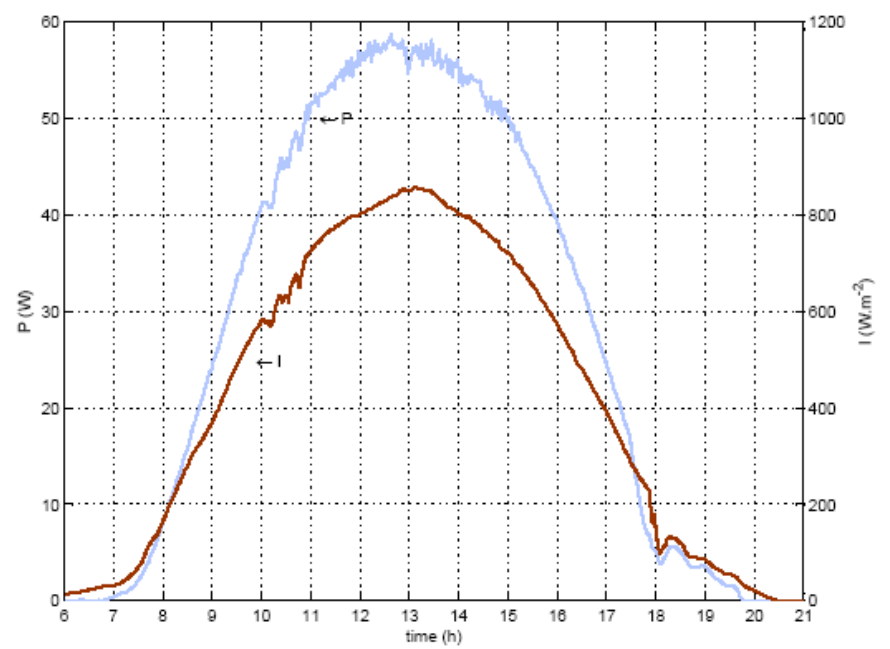

Fig. 28. Power characteristic of PV panel and intensity of falling radiation. 


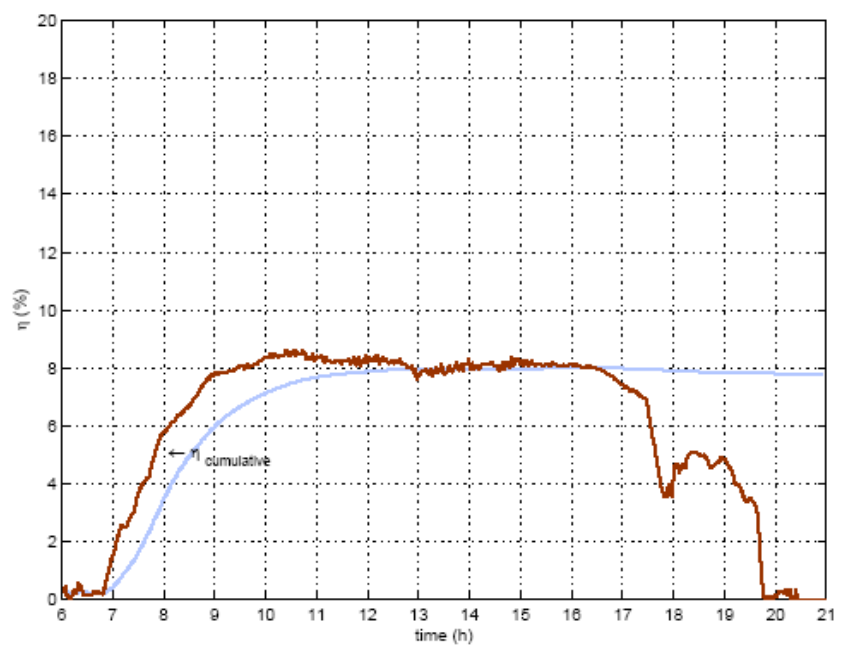

Fig. 29. Average and immediate efficiency of PV panel energy transformation.

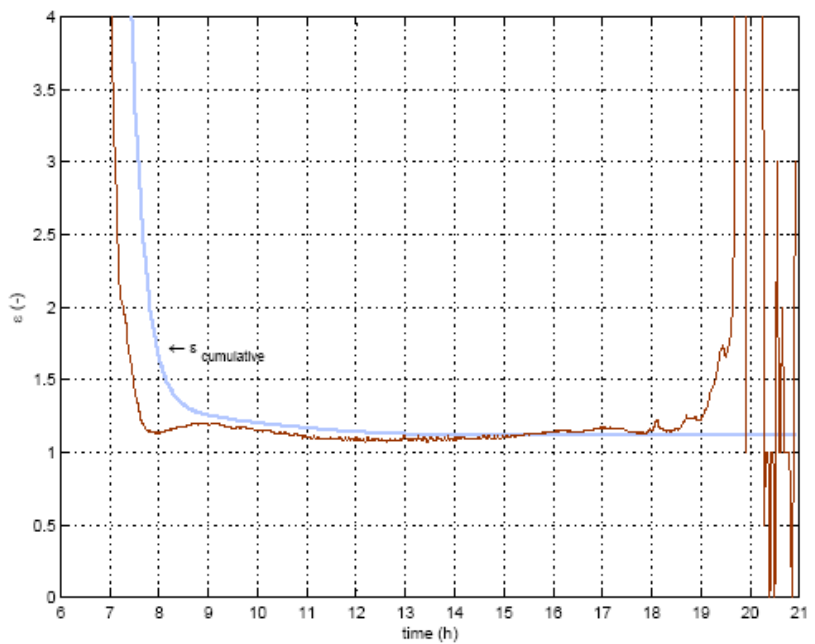

Fig. 30. Average and immediate gain from optimization of PV panel load. 


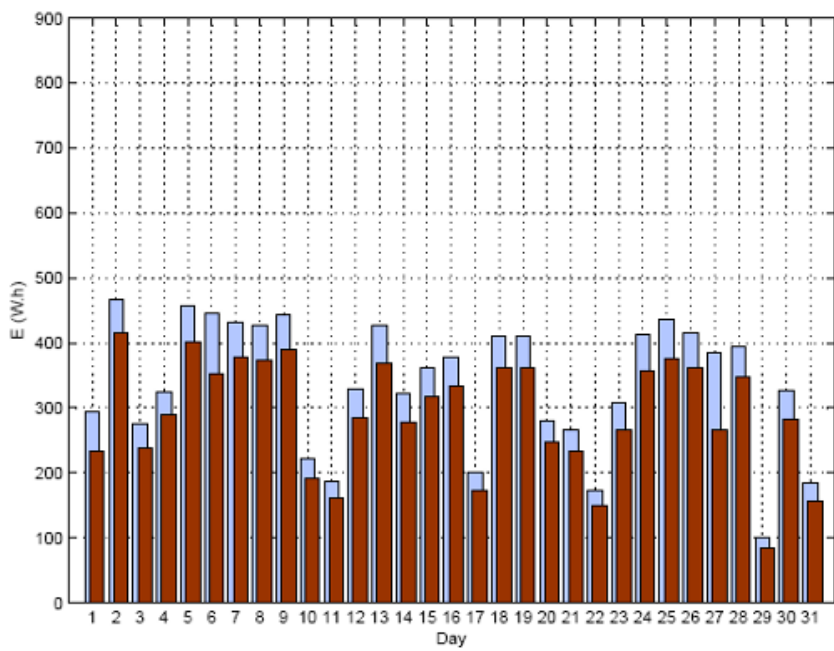

Fig. 31. Daily energy produced on individual days of a specific month.

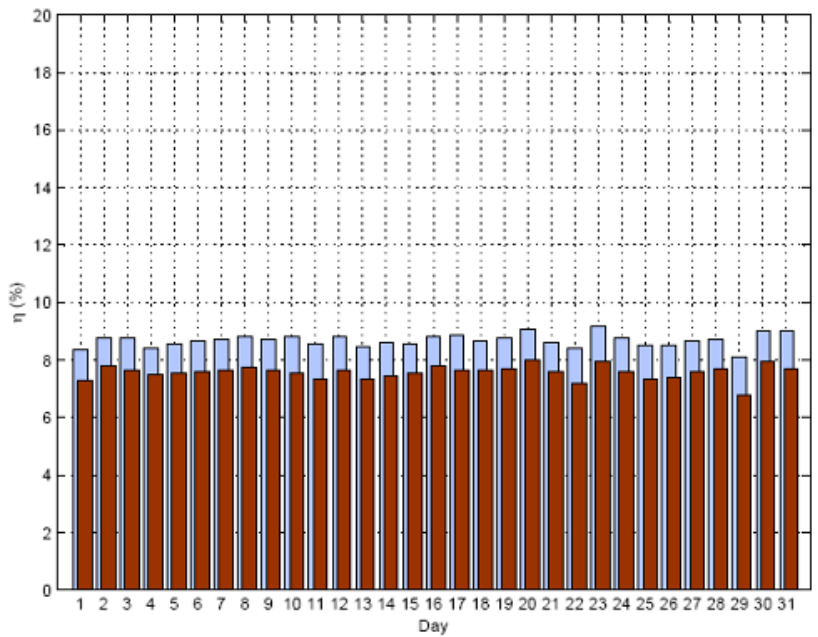

Fig. 32. Efficiency of PV panel energy transformation on individual days within a month. 


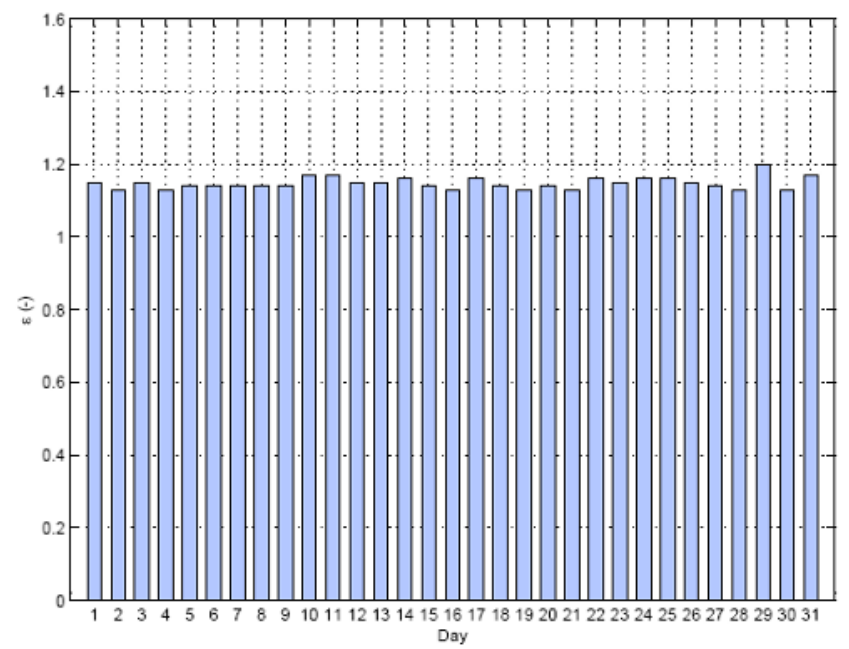

Fig. 33. Gain from optimization of PV panel load in individual days in a month.

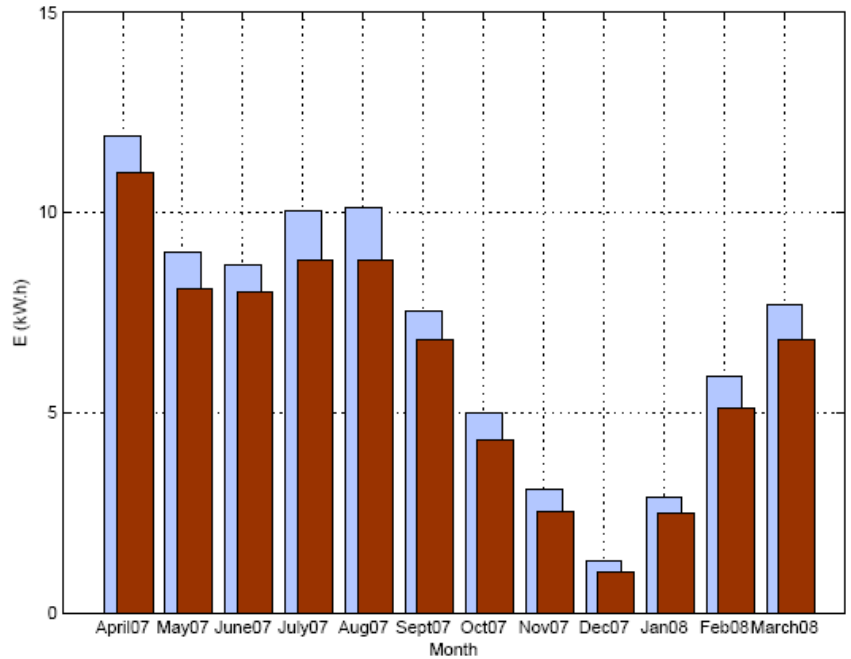

Fig. 34. Energy produced in individual months in a year. 


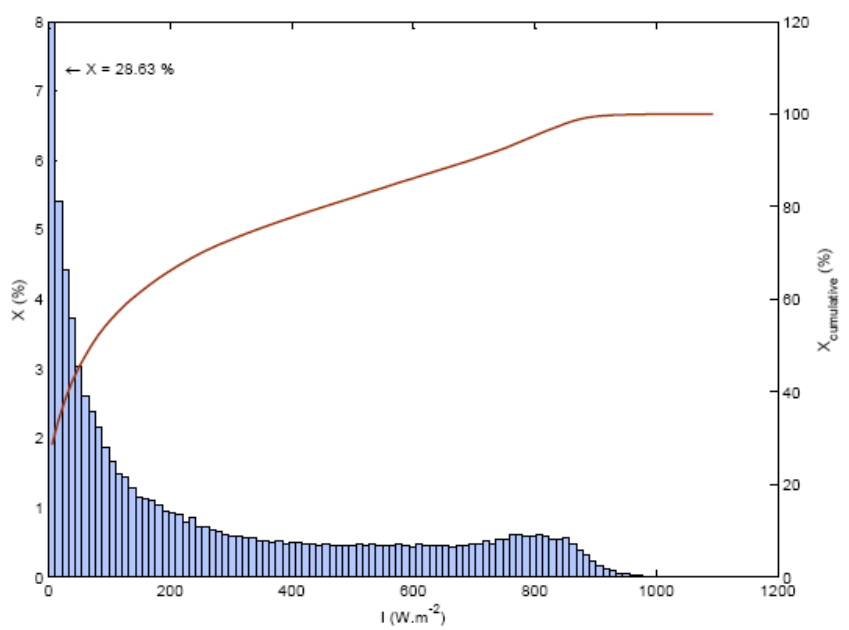

Fig. 35. Histogram of falling radiation intensity from all annual measured values.

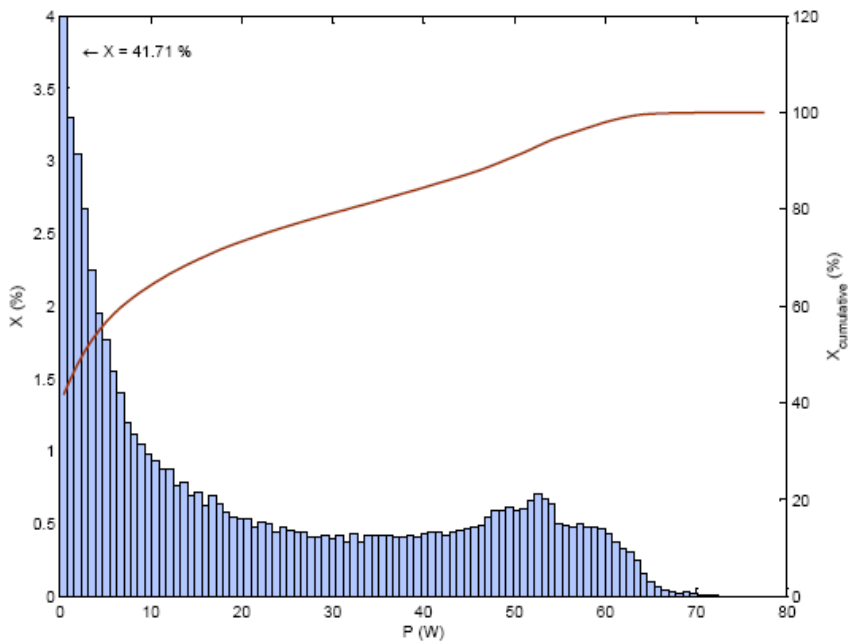

Fig. 36. Histogram of panel power from all annual measured values. 


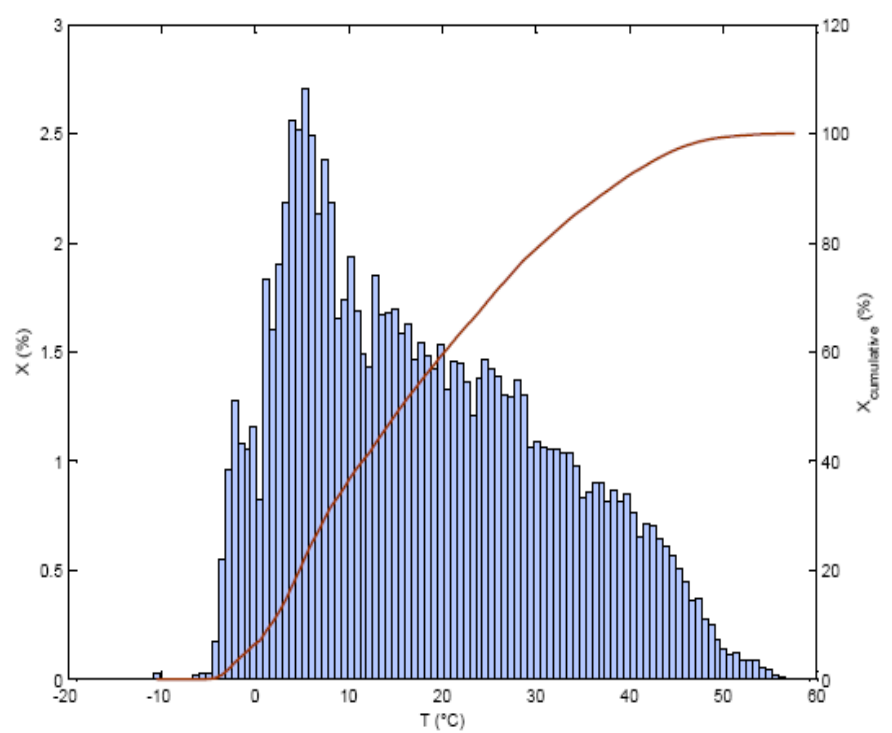

Fig. 37. Histogram of panel temperatures from all annual measured values.

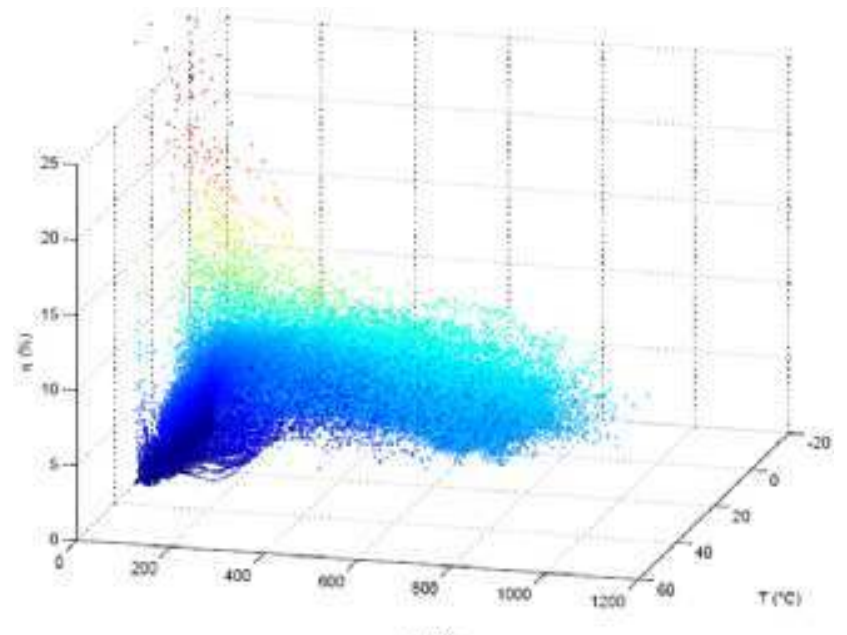

$\left(n \rightarrow x^{2}\right)$

Fig. 38. Function of dependence of energy transformation efficiency on temperature and intensity of falling radiation. 
The Temperature Dependant Efficiency of Photovoltaic

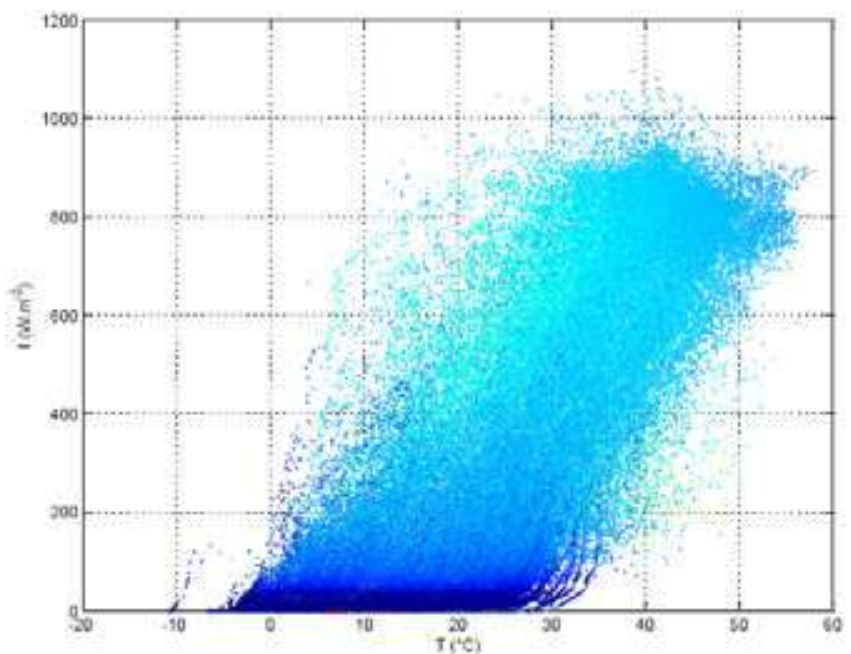

Fig. 39. Projection of previous dependence in 2D x / y axes. Dependence of temperature on intensity of falling radiation.

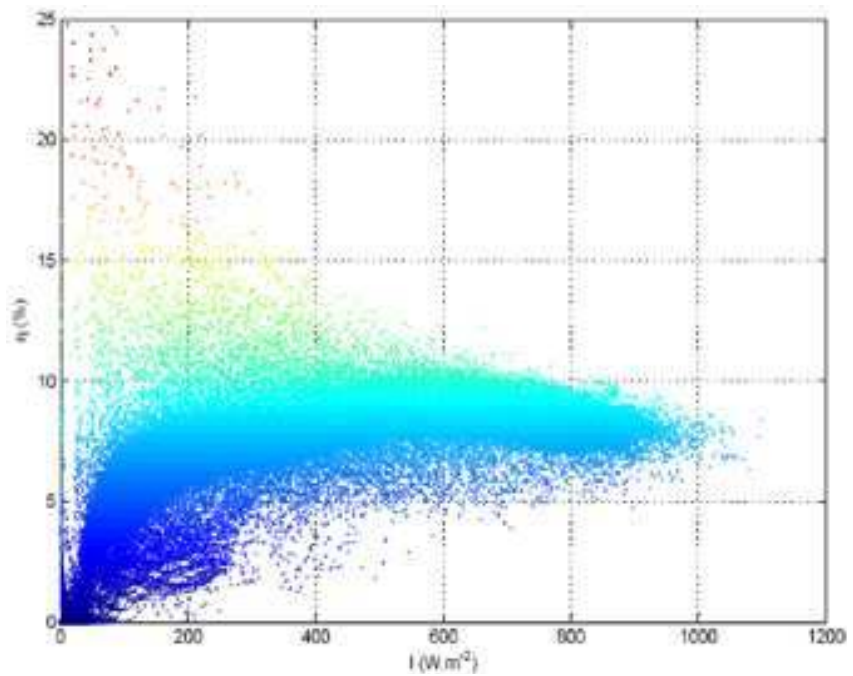

Fig. 40. Dependence of panel efficiency on intensity of falling radiation. 


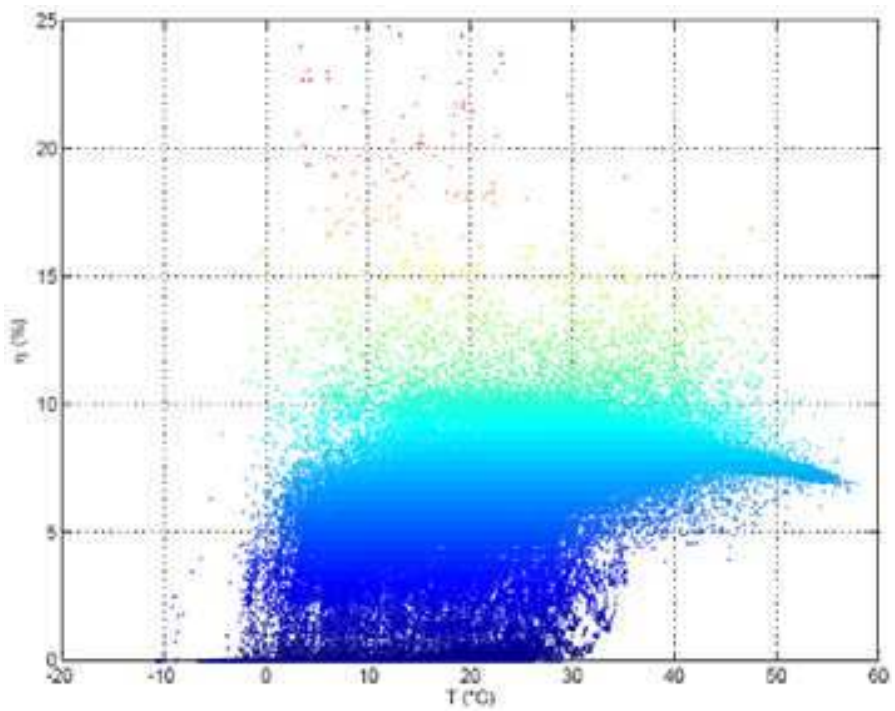

Fig. 41. Last dependence is the relation of panel efficiency and panel temperature.

The included diagrams present an outcome of the statistical analysis of long-term measurement, as could be possibly conducted for such measurements taken over long enough periods of time. Of course the more measurements will be processed within the analysis, the more relevant the results will be. Our system has been in operation, with several smaller breaks, since February 2007, which now represents two years of measurements, i.e. hundreds of thousands of values put into the database.

Besides the results presented there is a possibility of making more additional calculations and drawing further dependences e.g. within random representative time periods, for selected ambient temperatures and panel temperatures etc., regrettably there was no space left for them in this paper. Nonetheless, we are planning to place these and further assessments on the measurement system webpages, so this will comprise comprehensive measurements with not just immediate assessment and display of data, but also with the complete analysis of the whole measurement completed so far, conducted from the longterm point of view.

\section{Conclusion}

The article is aimed at making the reader aware of quite important problems relating to increasing the efficiency of solar panels, long-term monitoring of their operation and impact of changes in operating conditions on the load characteristics.

Today, disinformation is frequently spread in the community as well as among professionals, concerning particularly the efficiency of PV panels and their actual usability. Measurements like those described in this paper should contribute to making decisions on introducing photovoltaic converters and not only these, but the renewable energy sources in general, where their operation makes real sense. 
Our measurement system applied in the analysis of operating conditions impact on the load characteristics of solar energy converters with optimizing their load, has now been in full operation for two and a half years - providing that its announced restructuring and upgrade have been completed by now - and is also presented on the Internet site of our laboratory (http://www.ueen.feec.vutbr.cz/laboratory-of-unconventional-energy-conversion), where the measured values are provided on-line. By doing so we are trying to verify the function of the system alone as well as that of the units constructed by us within long-term measurements. Great amounts of data, approx. thousands of values, allow us to make calculations for which long-term data is needed, such as monthly and yearly summaries.

An advantage of this system of measurement and collection of data is its simplicity and easy adaptation to other measurement tasks, which involves a simple modification of a Matlab control script, creation of a new database for storing measured values and creation of a webpage for presentation of measurement results.

\section{Acknowledgements}

This paper includes results of the research financed by the Ministry of Education, Youth and Sport of the Czech Republic within Project MSM0021630516.

\section{References}

Bařinka R. and Klimek P. Obnovitelné zdroje energie pro ČR - část Postupný rozvoj využití sluneční energie fotovoltaickou technologií ("Renewable energy sources for CR Part Gradual Development of solar energy use by means of photovoltaic technology“) [online]. Praha: ČEZ, 2007. 186 pp. Available from URL: $<$ http://www.cez.cz/cs/vzdelavani/pro-profesionaly/odbornepublikace/8.html>.

Chen YM, Lee $\mathrm{CH}, \mathrm{Wu} \mathrm{HC}$. Calculation of the optimum installation angle for fixed solar-cell panels based on the genetic algorithm and the simulated annealing method. IEEE Trans Energy Converse 2005;20(2):467-73.

Chan DSH, Phillips JR, Phang JC. A comparative study of extraction methods for solar cell model parameters. Solid State Electron 1986;29:329-37.

Dobiáš, P. Fotovoltaika v městských aglomeracích. ("Photovoltaics in conurbations”) Brno: Brno University of Technology, Faculty of electrical engineering and communication technologies. Department of electrical power engineering, 2008. 90 pp., Appendices 13 pp. Bachelor's degree thesis supervisor: Ing. Petr Mastný, Ph.D.

Limbra M. and Poulek V. Solární energie (Solar Energy) [book]. Praha: ČZU, 2006. xxx s ISBN: 80-213-1488-5.

Limbra M. and Poulek V. Solární energie (Solar Energy) [book]. Praha: ČZU, 2005. 122 pp. ISBN: 80-213-1335-8.

Luque A, Hegedus S. Handbook of photovoltaic science and engineering. Berlin: John Wiley \& Sons Ltd.; 2002. pp. 87-111.

Markvart T. Solar electricity. 2nd ed. Berlin: John Wiley \& Sons Ltd.; 2000. p. 5-18.

Murtinger K., Beranovský J. and Tomeš M. Fotovoltaika. Elektřina ze slunce ("Photovoltaics. Electricity from the Sun.") [book]. Brno: ERA Publishers, 2007. 100 pp. ISBN: 97880-7366-100-7. 
Tian Pau Chang, Output energy of a photovoltaic module mounted on a single-axis tracking system, Applied Energy, Volume 86, Issue 10, October 2008, Pages 2071-2078, ISSN 0306-2619,DOI: 10.1016/j.apenergy.2009.02.006. (http://www.sciencedirect.com/ science/article/B6V1T-4VT5CRD-3/2/0fa247e9cc03116bc5ef8b87fdd79930)

U.S. Department of Energy - Energy Efficiency and Renewable Energy, Solar Energy Technologies Program PV Connected to the Utility Grid [online]. 2006, last update 5 January 2006 [quot. 24 March 2008]. Available from URL: <http:// www1.eere.energy.gov/solar/grid connect.html>. 


\section{Renewable Energy}

Edited by $\mathrm{T} \mathrm{J}$ Hammons

ISBN 978-953-7619-52-7

Hard cover, 580 pages

Publisher InTech

Published online 01, December, 2009

Published in print edition December, 2009

Renewable Energy is energy generated from natural resources-such as sunlight, wind, rain, tides and geothermal heat-which are naturally replenished. In 2008 , about $18 \%$ of global final energy consumption came from renewables, with $13 \%$ coming from traditional biomass, such as wood burning. Hydroelectricity was the next largest renewable source, providing $3 \%$ (15\% of global electricity generation), followed by solar hot water/heating, which contributed with 1.3\%. Modern technologies, such as geothermal energy, wind power, solar power, and ocean energy together provided some $0.8 \%$ of final energy consumption. The book provides a forum for dissemination and exchange of up-to-date scientific information on theoretical, generic and applied areas of knowledge. The topics deal with new devices and circuits for energy systems, photovoltaic and solar thermal, wind energy systems, tidal and wave energy, fuel cell systems, bio energy and geo-energy, sustainable energy resources and systems, energy storage systems, energy market management and economics, off-grid isolated energy systems, energy in transportation systems, energy resources for portable electronics, intelligent energy power transmission, distribution and inter-connectors, energy efficient utilization, environmental issues, energy harvesting, nanotechnology in energy, policy issues on renewable energy, building design, power electronics in energy conversion, new materials for energy resources, and RF and magnetic field energy devices.

\section{How to reference}

In order to correctly reference this scholarly work, feel free to copy and paste the following:

Jan Machacek, Zdenek Prochazka and Jiri Drapela (2009). The Temperature Dependant Efficiency of Photovoltaic Modules - a Long Term Evaluation of Experimental Measurements, Renewable Energy, T J Hammons (Ed.), ISBN: 978-953-7619-52-7, InTech, Available from:

http://www.intechopen.com/books/renewable-energy/the-temperature-dependant-efficiency-of-photovoltaicmodules-a-long-term-evaluation-of-experimental-

\section{INTECH}

open science | open minds

\section{InTech Europe}

University Campus STeP Ri

Slavka Krautzeka 83/A

51000 Rijeka, Croatia

Phone: +385 (51) 770447

Fax: +385 (51) 686166

\section{InTech China}

Unit 405, Office Block, Hotel Equatorial Shanghai

No.65, Yan An Road (West), Shanghai, 200040, China 中国上海市延安西路65号上海国际贵都大饭店办公楼405单元

Phone: +86-21-62489820

Fax: $+86-21-62489821$ 
www.intechopen.com 
(C) 2009 The Author(s). Licensee IntechOpen. This chapter is distributed under the terms of the Creative Commons Attribution-NonCommercial-ShareAlike-3.0 License, which permits use, distribution and reproduction for non-commercial purposes, provided the original is properly cited and derivative works building on this content are distributed under the same license. 